\title{
Scale factor management in the studies of affine models of shockproof garment elements
}

\author{
Oleg Denisov ${ }^{1}$, Mikhail Pleshko ${ }^{1,2^{*}}$, Irina Ponomareva $^{3}$ and Vitaliy Merenyashev ${ }^{1}$ \\ ${ }^{1}$ Don State Technical University, Gagarina sq.1, Rostov-on -Don, 344010, Russia \\ ${ }^{2}$ Rostov State Transport University, Rostovskogo Strelkovogo polka narodnogo opolcheniya sq., 2, \\ Rostov-on-Don, 344038, Russia \\ ${ }^{3}$ Southern Federal University, Bolshaya Sadovaya st.105/42, Rostov-on-Don, 344006, Russia
}

\begin{abstract}
New samples of protective garment for performing construction work at height require numerous tests in conditions close to real conditions of extreme vital activity. The article presents some results of shockproof garment element studies and a description of a patented prototype. The tests were carried out on a model which geometric dimensions were convenient for manufacturing it in a limited batch. In addition, the used laboratory equipment (for example, a unique power pendulum), blanks made of a titanium-nickel alloy with a shape memory effect also imposed their limitations. The problem of the adequacy of the obtained experimental results transfer to mass-produced products was solved using tools of the classical similarity theory. Scale factor management influence in the affine modeling of the shockproof element, studied on the basis of the equiatomic titanium-nickel alloy with the shape memory effect, allowed us to assume, with a sufficient degree of reliability, the technical possibility of extrapolating the results of experimental studies to full-scale objects for the formation of the initial data of the mathematical model of shockproof garment dynamics elastoplastic deformation (while observing the similarity of the features of external loading).
\end{abstract}

\section{Introduction}

The Russian Federation is currently implementing the national standard GOST P 54934 - 2012 "Occupational safety and health management systems", however, statistics highlight some increase in occupational morbidity. For occupations characterized by an increased risk of injury, it is possible to get a large joint injury at the workplace. It is described that when jumping and falling at the moment of landing, forces, that exceed its weight by almost five times, affect on the body. Incorrect landing, especially in combination with twisting in the knee joint, as a rule, leads to micro- and macro-injuries of the joint, which causes further development of pathology, including a decrease in the quality of life and disability. The construction works at a height are of particular concern [1-7,14].

A sufficient number of different protective aids are used for the prevention of injuries, the most convenient of which are the knee pads [8]. However, at the present time, the use of

\footnotetext{
* Corresponding author: mixail-stepan@mail.ru
} 
such protective devices is not widespread for common use (except for athletes), in addition, there are practically no means to protect large joints in occupations that are characterized by an increased risk of injury, innovative technical solutions and materials of increased protection and effectiveness are rarely used [3, 4, 17].

When analyzing modern technical solutions that underlie the domestic means of personal protection of personnel $[13,16]$, it was found that there is a large number of them. Most of them describe elastic-plastic elements, such as elastic bandages, lamellar materials, soft fittings. All of them, as a rule, are made in the form of an elastic deformable element based on soft polyurethane and / or gel. However, all existing samples can be further developed for more optimal use towards the efficiency of shock absorption increase, the energy capacity increase for example, due to the operation of the damping element of the material used, not only in the elastic but also in the plastic deformation regions, the inclusion of rational energy-absorbing elements in the protective devices. along with the implementation of tasks to reduce the overall size of the model.

The solution of this problem calls for the determination of methods and technical devices that facilitate a convenient and rapid change of fixation points on garment, as well as the need to investigate the possibility of transferring the results of field experiments and theoretical calculations to real industrial samples of shockproof elements.

\section{Initial data}

Let us consider some results of experimental studies to determine the power characteristics of the shock protection elements made on the basis of elastic-plastic inserts made of the alloy with shape memory effect.

The test of the prototype model of the shockproof device was carried out on the drop crusher (GOST 10708-82), specially modified for the present studies at different temperature regimes, accompanying work in various climat and production conditions. During the experiment, at a given temperature, the rotation moment and the magnitude of the shift strain were measured. The temperature of the helix of the model was subjected to controlled changes by application of an electric contact heater, measured with a digital thermometer (GOST P 8.625-2006). The signal was transferred from a thermocouple, the junction was fixed according to a conventional technique [12].

Peculiarities of the experimental procedure: a model of a shockproof device matched to the size, was worn on the basis, imitating the model of the knee joint of a human. As a test model, the following adaptation was used.

The developed scale model of a shockproof garment element (Fig. 1) was an overlay fastened with a velcro fastener and a protective and decorative valve. The model included a base in the form of spirals from an equiatomic titanium-nickel alloy with shape memory effect. The base was made in the form of wire helices of a flat section with risks along the entire length and included in an elastic deformable element of silicone, which made it possible to perform a relative spatial fixation of the spiral in the base, to provide the required distance between the turns of the spiral, and also to participate in the absorption of the impact energy. The base on both sides was covered with a perforated heat-conducting tape based on a copper alloy, with C-shaped or U-shaped "petals" and on one side equipped with a textile velcro, and on the other side the fabric had a slotted punching. 


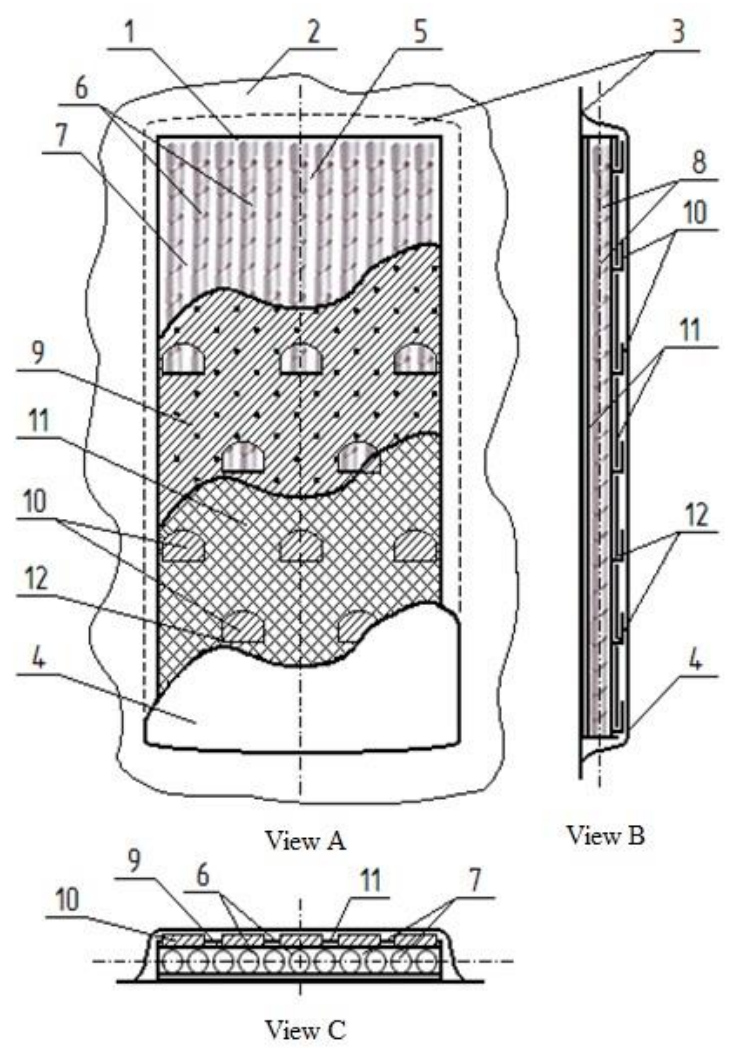

Fig. 1. Shockproof garment element.

Legend: 1 - shockproof element, 2 - garment, 3 - velcro, 4 - fabric decorative and safety valve with velcro, 5 - base of the shockproof garment element, 6 - wire helices of flat section with risks along the entire length of the equiatomic titanium nickel alloy with shape memory effect, 7 - elastic deformable element of silicone, 8 - spiral turn, 9 - thermal conductive tape based on copper alloy perforated with micro holes and $\mathrm{C}$ or U-shaped holes, 10 - "petals" of heat-conducting tape based oncopper alloy Cor U-shaped, 11 - fabric with slotted holes, 12 - slotted punching of fabric.

The experimental design was developed in accordance with the standard method for evaluating the energy absorption for plastic-elastic elements of similar systems $[4,10,11]$.

It was experimentally established that when the impact of a drop crusher with a working area of $\mathrm{S}_{\mathrm{y}}-1 \cdot 10^{-3} \mathrm{~m}^{2}\left(1000 \mathrm{~mm}^{2}\right)$, about $150 \ldots 200$ turns were deformed in the elastoplastic region, absorbing in total about $150 \ldots 180 \mathrm{~J}$, and taking into account the deformation of the elastic filling of the fabric support base - up to $200 \ldots 240 \mathrm{~J}$ of impact energy.

In order to determine the characteristics of energy absorption at different temperatures, one of the stages of the study included testing with the measurement of dynamic characteristics in correlation with heating of the deformed elements.

The main results of the experiment:

1. The energy-absorbing capacity of given plastic elements with shape memory effect to a large extent correlates with temperature (Fig. 2).

2. The actual energy absorption is in the range of more than $100 \mathrm{~J}$.

3. The nature of the curves is practically repeated for various shock loads up to critical ones. 


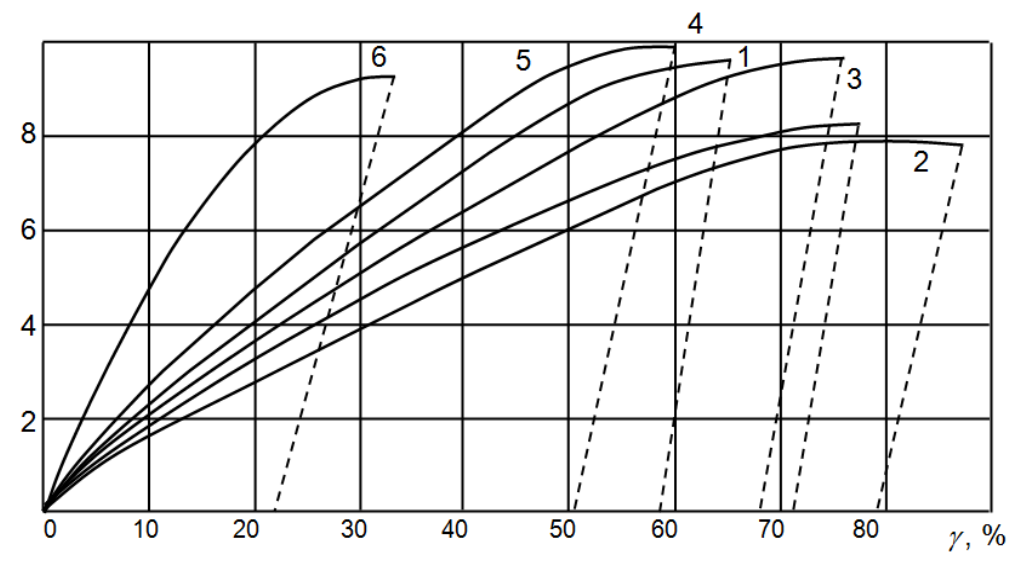

Fig. 2. Conditional stress-strain diagrams of the model based on the TiNi-1 alloy under shift (torsion) and high. Legends: 1 - $300 \mathrm{~K} ; 2$ - $320 \mathrm{~K} ; 3$ - $325 \mathrm{~K}$; 4-335 K; 5 - $355 \mathrm{~K} ; 6$ - $385 \mathrm{~K}$ (dashed: elastic discharge)

It is known $[4,14]$ that an energy impact of more than $100 \mathrm{~J}$ can become dangerous for a human, therefore, a capacity for energy absorption of about $150-200 \mathrm{~J}$ is nominal for a technical protective device.

Based on the results of the field experiment, the features of the expected operation of the real device are determined. In case of shock, at first, deformations of the model elements occur in the elastic region, ensuring the absorption and dispersion of the shock energy. When the shock effect exceeds the level of elastic deformation of the protection elements, the outer layers of the model collapse to the limiting states of elastic hysteresis, and the spiral wires of the device are deformed elastically, and then plastically. It is established that the deformations of spiral wires are accomplished due to twisting of single turns and elastoplastic bending and torsion at a nonlinear impact site. In this case, the elastoplastic deformation of the site results in the greatest absorption of the shock energy $[8,9,15,16]$.

It is shown that with an increase in the number of cycles of shock deformation, a gradual decrease in the degree of restoration of the original dimensions of the model is observed, up to a certain stabilization of the value. As the shift strain amplitude is increased, the degree of reduction of the shape is reduced, and more cycles are required to achieve stabilization. In practical application, single strokes are typical, under which, obviously, there will be a stable recovery of the sample. It is possible to explain this behavior of the TiNi elastic-plastic element by non-dislocation deformation mechanisms, which correlates with the literature data and the results of studies of the mechanical memory effect $[3,9,10]$.

\section{The calculation results}

The processing of the results of experiments of scale models showed the principal possibility of transferring the results of the experiment to real shockproof elements based on the use of a system of dimensionless complexes.

To estimate the influence of the scale factor, the results of the model tests were presented in the form of relations between the similarity criteria [6]. The linear dimensions and other characteristics are considered as characteristic parameters: the length of the section subjected to the effect $l$, the radius of the twisting of the spirals $R$, the value of the external force (per unit length) of the force action $F$, the relative linear strain of the 
experimental model of the shockproof device $\varphi$, the relative linear deformation of the model of the shockproof device in the elastic zone $\varphi_{\Pi}$, the integral ultimate strength of the materials of the model of the shockproof device in the zone of elastic deformation $G$, the integral model of the tensile strength of materials in the elastoplastic deformation zone shockproof device $\Phi$. As a result, the following main parameters adopted:

$$
F, l, R, G, \Phi, \phi, \phi_{\Pi},
$$

which dimensions are represented on the basis of the similarity theory [6] in the form of a matrix:

$$
\mid \begin{array}{rrrrr}
2 & 1 & 1 & -1 & -1 \\
1 & 0 & 0 & 1 & 1 \\
-2 & 0 & 0 & -2 & -2
\end{array} \|,
$$

and the dimensionless parameters $\varphi$ and $\varphi_{\Pi}$ are not included in this determinant.

It is important to determine the number of independent dimensionless dependencies associated with a given matrix. It is equal to $n-r=5-2=3$, where $r$ is the rank of the matrix (2).

To create a system of dimensionless complexes, the matrix is transformed into the following form:

$$
\left\|\begin{array}{rrrrr}
1 & 0 & -1 & 0 & -3 \\
0 & 1 & 0 & 0 & -1 \\
0 & 0 & 1 & -1 & 0
\end{array}\right\| .
$$

Using the matrix (3) presented above and angular quantities $\varphi$ и $\varphi_{\Pi}$, a system of dimensionless complexes is now compiled in the form of similarity criteria:

$$
\Pi_{1}=\frac{F}{G R^{3}}, \quad \Pi_{2}=\frac{l}{R}, \quad \Pi_{3}=\frac{G}{\Phi}, \Pi_{4}=\varphi, \Pi_{5}=\varphi_{\Pi} .
$$

In this case, the first dimensionless complex was considered as a known similarity law, analogous to the formulation of Kirpichev-Barb-Kik [12].

As the main characteristic size, the radius of the spirals $R$ is adopted, and the length of the linear section subjected to the influence $l$ of the experimental model 1 and the real object 2 is expressed in terms of the ratio:

$$
L_{i}=K_{i} R_{i}, \quad i=1,2 .
$$

Then:

$$
\frac{l_{1}}{R_{1}}=\frac{l_{2}}{R_{2}}=K_{1}=K_{2}=K .
$$

Using (6), we present a system of equations for elastoplastic deformation of models in the form:

$$
\begin{aligned}
& F_{i}=\frac{\pi}{2 K} D_{i}, \quad i=1,2, \ldots \\
& D_{i}=\left\{\begin{array}{l}
G_{i} R_{i}^{3} \varphi_{i}, \varphi_{i}<\varphi_{n i} \\
G_{i} R_{i}^{3}\left[\frac{4}{3}\left(\varphi_{n i}-\frac{4 \varphi_{n i}^{4}}{\varphi_{i}^{3}}\right)+\right.
\end{array}\right. \\
& \left.+\frac{\Phi_{i}}{G_{i}}\left(\varphi_{i}-\varphi_{n i}\right)\left(1-\frac{\varphi_{n i}^{4}}{\varphi_{i}^{3}}\right)+\frac{\varphi_{n i}^{4}}{\varphi_{i}^{3}}\right], \varphi_{i} \geq \varphi_{n i} .
\end{aligned}
$$


For geometrically similar samples 1 and 2 scales of spiral radii $R_{0}$, relative linear strain $\varphi_{0}$, integral strength limits of the materials of the shockproof device model in the zones of elastic and elastoplastic deformation $G_{0}$ and $\Phi_{0}$ were introduced:

$$
\begin{gathered}
R_{0}=\frac{R_{1}}{R_{2}} ; \varphi_{0}=\frac{\varphi_{1}}{\varphi_{2}} ; \quad G_{0}=\frac{G_{1}}{G_{2}} ; \\
\Phi_{0}=\frac{\Phi_{1}}{\Phi_{2}} ; \varphi_{\text {по }}=\frac{\varphi_{\text {п1 }}}{\varphi_{\text {п2 }}}
\end{gathered}
$$

In this case we consider the conditions of external loading models, in which the relationships remain constant applied external linear power effects:

$$
\frac{F_{1}}{F_{2}}=F_{0}=\text { const }
$$

Using the scales (8), the condition of simple loading of torsions (9), by geometric similarity, transformed (7) into a dimensionless form:

$$
\begin{aligned}
& \frac{F_{0} F_{2}}{G_{0} R_{0}^{3} G_{2} R_{2}^{3}}=\frac{\pi \phi_{0} \phi_{2}}{2 K} \text { при } \phi_{0} \phi_{2}<\phi_{\text {по }} \phi_{\text {п2} 2} \text {. } \\
& \frac{F_{\mathrm{o}} F_{2}}{G_{0} R_{0}^{3} G_{2} R_{2}^{3}}=\frac{\pi}{2 K}\left[\begin{array}{c}
\frac{4}{3}\left(\phi_{\text {по }} \phi_{\text {п2 }}-\frac{\left(\phi_{\text {по }} \phi_{\text {п2 }}\right)^{4}}{4\left(\phi_{\text {по }} \phi_{\text {п2 } 2}\right)^{3}}\right)+ \\
+\frac{\Phi_{0} \Phi_{2}}{G_{0} G_{2}} \times\left(\phi_{0} \phi_{2}-\phi_{\text {по }} \phi_{\text {п2 } 2}\right) \times \\
\times\left(1-\frac{\left(\phi_{\text {по }} \phi_{\text {п2 } 2}\right)^{4}}{4\left(\phi_{\text {по }} \phi_{\text {п2 } 2}\right)^{4}}+\frac{\left(\phi_{\text {по }} \phi_{\text {п2 } 2)^{4}}\right.}{\left(\phi_{\text {по }} \phi_{\text {п2 } 2}\right)^{3}}\right)
\end{array}\right] \\
& \text { при } \varphi_{0} \varphi_{2} \geq \varphi_{\text {по }} \varphi_{\text {п2 }} \text {; } \\
& \frac{F_{2}}{G_{2} R_{2}^{3}}=\frac{\pi \phi_{2}}{2 K} \text { при } \phi_{2}<\phi_{\text {п2 }} \text {; } \\
& \frac{F_{2}}{G_{2} R_{2}^{3}}=\frac{\pi}{2 K}\left[\begin{array}{l}
\frac{4}{3}\left(\phi_{\mathrm{n} 2}-\frac{\phi_{\mathrm{n} 2}^{4}}{4 \phi_{2}^{3}}\right)+\frac{\Phi_{2}}{G_{2}}\left(\phi_{2}-\phi_{\mathrm{n} 2}\right) \times \\
\times\left(1-\frac{\phi_{\mathrm{n} 2}^{4}}{\phi_{2}^{4}}\right)+\frac{\phi_{\mathrm{n} 2}^{4}}{\phi_{2}^{3}}
\end{array}\right]
\end{aligned}
$$

where $\varphi_{2} \geq \varphi_{\Pi 2}$.

In experiments with models of prototypes of shockproof devices [6], the second dimensionless complex was changed. The remaining similarity criteria remained constant. In Figure 3, for the fixed values of the similarity criteria from the results of several experiments, a simple criterion equation was created $\frac{F}{G R^{3}}=f\left(\frac{l}{R}\right)$.

As the value of the second dimensionless complex decreases, the nonlinear effect of plastic hardening degenerates.

During the test of the models, the change in the heating temperature of the samples can also significantly affect the mechanical properties of the power elements of the shockproof device. 


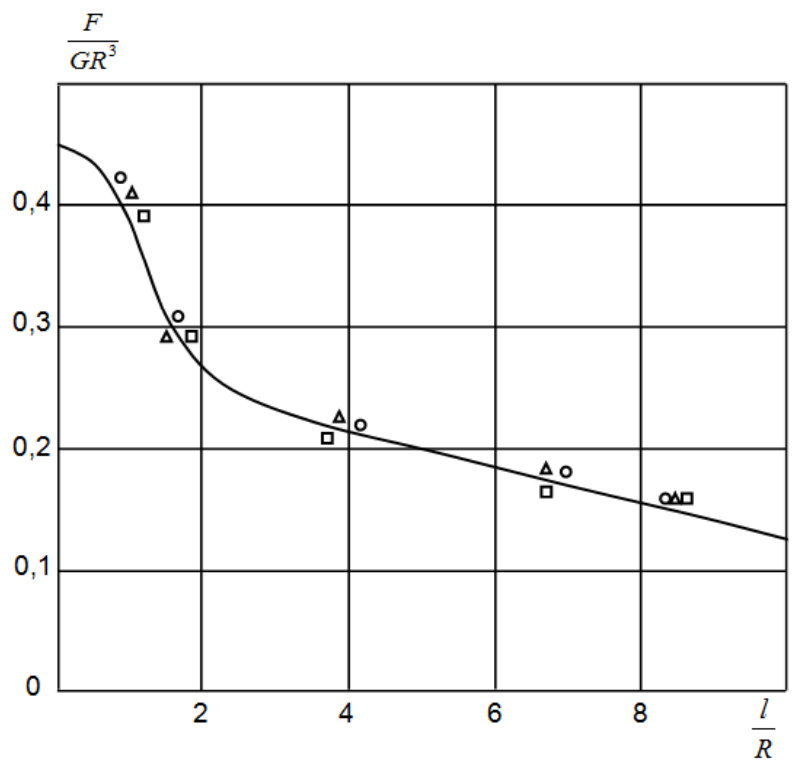

Fig.3. Experimental values of dimensionless power characteristics of models in the criterial form.

The experiments were processed in a wide temperature range in the criterial form $\frac{F}{G R^{3}}=f\left(\frac{l}{R}, \varphi_{\Pi}\right)$.

An assessment of the scale factor influence on the possibility of transferring the results of experimental studies to real objects showed a good agreement of the criteria in the given region of deformation. In this case, the discrepancies for model samples amounted to no more than $15-20 \%$ with a confidence coefficient of 0.95 , which can be explained by the difference in the nonlinearity of hardening in elastoplastic deformations in models based on an alloy with phenomenal properties. The nonlinearity of the criterial dependence in this case is a consequence of the special and random nature of the external forces applied to the experimental models.

\section{Conclusions}

Thus, the evaluation of the scale factor effect in the simulation of a shockproof garment element based on the alloy with shape memory effect makes it possible to extrapolate the results of experimental studies to other objects to form the initial data of the mathematical model of the dynamics of elastoplastic deformation of shockproof devices while observing the similarity of the external loading characteristics.

An integrated approach to the investigation of individual shockproof elements placed on garnet can contain such key points as:

- study of information on similar samples used in production, sports, life;

- development of sketches and approval of the pilot design of the device;

- selection of structural materials with the definition of the range of major suppliers;

- production of prototypes;

- carrying out full-scale experiments;

- an assessment of the possibilities to transfer the experimental results to real objects;

- marketing research of the industrial production possibility. 


\section{References}

1. A. E. Astvatsaturov et al. Obespechenie bezopasnosti pri tehnogennyh i prirodnyh chrezvychajnyh situacijah. (Rostov n/D: DSTU, 2004).

2. O. V. Denisov et al. Inzhenernyj vestnik Dona: Jelektronnyj nauchnyj zhurnal. 2. (2017).

3. O. V. Denisov et al. IOP Conference Series: Earth and Environmental Science. "Ecology and Safety in the Technosphere: Current Problems and Solutions". 012044. (2017).

4. O. V. Denisov et al. Sbornik nauchnyh trudov nauchno-metodicheskoj konferencii, posvjashhennoj 85-letiju DSTU (Rus) [Innovative technologies in science and education: Collection of scientific works scientific-methodical conference]. Rostov on/D (2015).

5. O. V. Denisov et al. Kompleksnaja bezopasnost' naselenija $i$ territorij $v$ chrezvychajnyh situacijah. Problemy i reshenija. (Rostov on/D: DSTU, 2016).

6. O. V. Denisov et al. Izvestija vuzov. Estestvennye nauki. 4. (1999).

7. O. V. Denisov et al. Materialy III Regional'noj nauchno-prakticheskoj konferencii Juzhnogo federal'nogo okruga. Krasnodar (2015).

8. I. I. Eremin, O. V. Denisov Inzhenernyj vestnik Dona: Jelektronnyj nauchnyj zhurnal. 36. (2-2). (2015).

9. Ya. B. Fridman, Mehanicheskie svojstva metallov. Ch.1. Deformacija i razrushenie (M.: Mashinostroenie, 1974).

10. A. I. Kostoglotov et al. Izvestija vuzov. Estestvennye nauki. 4. (1999).

11. A. A. Kozlov, et al. Vestnik Sankt-Peterburgskogo gosudarstvennogo universiteta tehnologii i dizajna. Serija 1: Estestvennye i tehnicheskie nauki. 2. (2016).

12. G.B. Iosilevich Prikladnaya mekhanika (Moskva: Vysshaya shkola, 1989).

13. Protivoudarnoe prisposoblenie: patent na izobretenie [Shockproof device: patent for invention]. B. Ch. Meshi, O. V. Denisov, Yu. I. Bulygin, A. E. Ponomarev, I. A. Ponomareva. No RUS 2578997. (08.2014).

14. B. A. Rabinovich Zhurnal avtomobil'nyh inzhenerov. 6 (2016).

15. A. G. Tihomirov,, et al. Izvestiya vysshih uchebnyh zavedenij. Severo-Kavkazskij region. Seriya: Estestvennye nauki (Rus). 3. (2004).

16. I. V. Topilin, I. A. Ponomareva, Inzhenernyj vestnik Dona: Jelektronnyj nauchnyj zhurnal. 36 (2-2) (2015).

17. V. V. Vershinin,, A.A. Loktev, Vestnik Permskogo nacional'nogo issledovatel'skogo politehnicheskogo universiteta. Mehanika. 1 (2011) 